\title{
Abnormal expression of CD79a, CD56 and CD7 in acute myeloid leukemia
}

\author{
Ghaleb Elyamany ${ }^{1,2 *}$, kamal Fadalla ${ }^{2}$ and Abdulaziz Al Abdulaaly ${ }^{2}$ \\ *Correspondence: ghalebelyamany@yahoo.com \\ 'Theodor Bilharz Research Institute, Department of Hematology and Blood Bank, Egypt. \\ ${ }^{2}$ Department of Adult Clinical Hematology and Stem cell Therapy, Prince Sultan Military Medical City, Saudi Arabia.
}

\begin{abstract}
Background: Flow cytometric analysis of leukemias improves accuracy for distinguishing acute leukemias of myeloid and lymphoid origin. In rare cases, both myeloid and lymphoid antigens are expressed, creating ambiguity for lineage assignment and difficulties in diagnosis of leukemia. Aberrant antigen expression in acute myeloid leukemia (AML) is recognized to be a poor prognostic indicator. CD79a is a highly lineage-specific marker of B lymphoid cells and plays an important role in the diagnosis of acute leukemia.

Methods: We report an unusual case of acute myeloid leukemia in which CD79a is clearly expressed along with other lymphoid antigens (CD7 and CD56) in addition to antigens denoting myeloid lineage. The characteristics of morphology, immunophenotype, molecular and cytogenetic of bone marrow samples were analyzed.

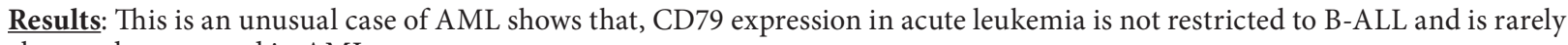
aberrantly expressed in AML.

Conclusions: The high score given to CD79a by EGIL is questionable based on cytogenetic classification. The prognostic relevance of expression of CD79a in AML is unclear and need further studies. The prognostic significance of selected markers of leukemic cells is well known, CD7 and CD56 expression at diagnosis has been associated with low remission rates and biological aggressiveness in a significant proportion of acute leukemias.
\end{abstract}

Keywords: Acute myeloid leukemia, CD79a aberrant expression, CD56 and CD7

\section{Introduction}

Immunophenotyping improves accuracy of acute leukemia classification and is considered particularly useful for identifying aberrant lineage association of acute leukemia, biphenotypic and bilineal acute leukemia, as well as monitoring minimal residual disease [1].

The European Group for the Immunological Characterization of Acute Leukemia (EGIL) developed a scoring system that ranges from 0.5 to 2.0 for the relative significance of cluster of differentiation (CD) antigens in determining the immunophenotype of leukemias Table 1 [2], use of this scoring system has been used mainly for the identification of leukemias of ambiguous lineage [3]. Two reported large series showed that, approximately $46 \%$ of acute lymphoblastic leukemia (ALL) cases and $48 \%$ of AML cases have aberrant expression of a single antigen associated with another cell lineage $[4,5]$, most commonly CD20 [3] and CD7 [6] in AML and CD33 in ALL [7].

Aberrant antigen expression in AML is recognized to be a poor prognostic indicator. CD56 and CD7 expression at diagnosis has been associated with low remission rates and biological aggressiveness in a significant proportion of acute leukemias [3].

CD79a is a subunit of an intracytoplasmic protein reported to be specific for $B$ lymphocytes. Few studies demonstrates that CD79a expression in acute leukemia is not restricted to
B-ALL and rarely aberrantly expressed in AML and T-ALL, [8-10]. In the EGIL system, CD79a is believed to be highly specific for B-lymphoid lineage. In fact, some authors have suggested that CD79a positivity is essentially diagnostic of ALL [11].

We report an unusual case of AML in which the blasts express CD79a, an antigen reported to be highly specific for B-lymphoid lineage with other antigens associated with lymphoid lineage (CD56 and CD7), along with antigens of myeloid lineage (CD117, CD33, and CD64).

\section{Materials and methods \\ Case report}

A 42-year-old man, known to be Diabetic, hypertensive, ischemic heart disease and chronic hepatitis (HBV), presented to our Hospital by mild fever, chronic cough, weight loss and loss of appetite 2 months ago, complete blood cell count (CBC) showed leucocytosis, and mild thrombocytopenia with circulating blasts in PB smear. On admission CBC information included the following: white blood cell count (WBC), $21.7 \times 10^{9} / \mathrm{L}$; neutrophils $5.6 \times 10^{9} / \mathrm{L}$; lymphocytes $5.9 \times 10^{9} / \mathrm{L}$; monocytes $2.0 \times 10^{9} / \mathrm{L}$; eosinophils $3.0 \times 10^{9} / \mathrm{L}$; basophils $0.2 \times 10^{9} / \mathrm{L}$; band $0.4 \times 10^{9} / \mathrm{L}$; and $21 \%$ blasts $\left(4.6 \times 10^{9} / \mathrm{L}\right)$, hemoglobin, $13.3 \mathrm{~g} /$ $\mathrm{dL}$; and platelet count, $117 \times 10^{9} / \mathrm{L}$. Accordingly, bone marrow aspirate and core biopsy were performed, and the sample 
Elyamany et al. Pathology Discovery 2013,

http://www.hoajonline.com/journals/pdf/2052-7896-1-6.pdf

Table 1. Scoring System for the Definition of Acute Leukemias of Ambiguous Lineage [Adapted from Bene et al., [2]].

\begin{tabular}{llll}
\hline Score & B-Lymphoid & T-lymphoid & Myeloid \\
\hline 2 & cCD79a & cCD3 or sCD3 & MPO \\
& cIgM & Anti-TCR & -- \\
& cCD22 & -- & -- \\
\hline 1 & CD19 & CD2 & CD117 \\
& CD20 & CD5 & CD13 \\
& CD10 & CD8 & CD33 \\
& -- & CD10 & CD65 \\
\hline 0.5 & TdT & TdT & CD14 \\
& CD24 & CD7 & CD15 \\
& -- & CD1a & CD64 \\
\hline
\end{tabular}

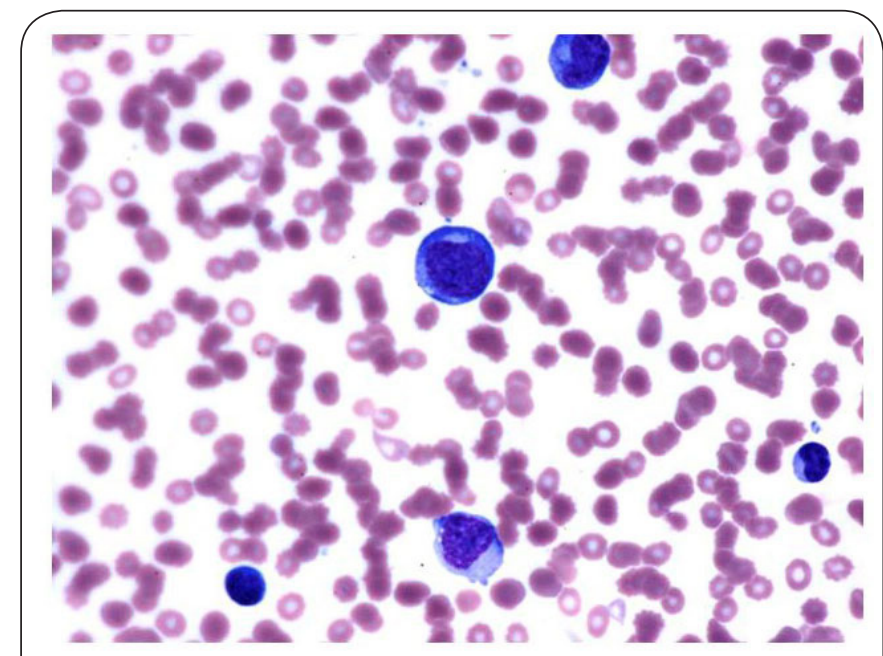

Figure 1. Peripheral blood (Wright-Giemsa stain) showing circulating blast cells which are medium to large size with dispersed chromatin with one or more nucleoli, the cytoplasm is relatively abundant with variable degree of basophilia.

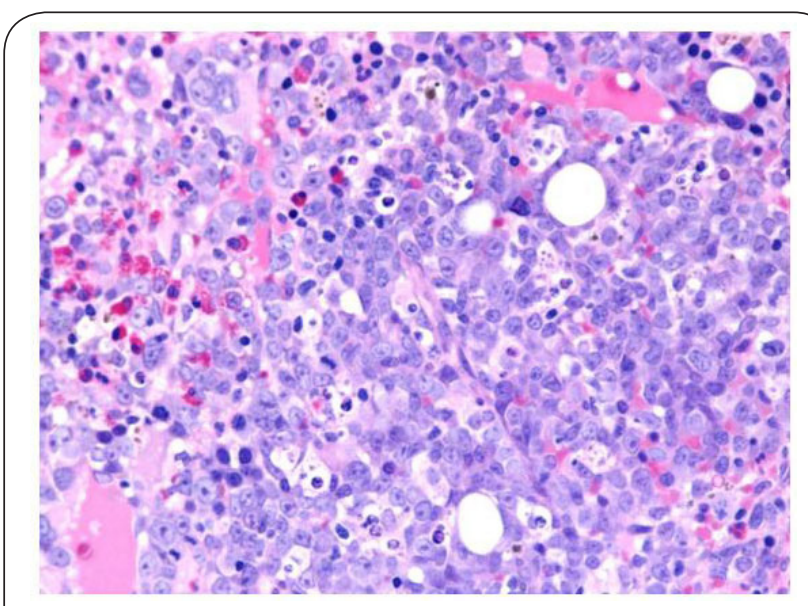

Figure 2. Low power of H\&E bone marrow trephine biopsy showing hypercellular marrow with infiltration by immature, mononuclear cells with one or more nucleoli.

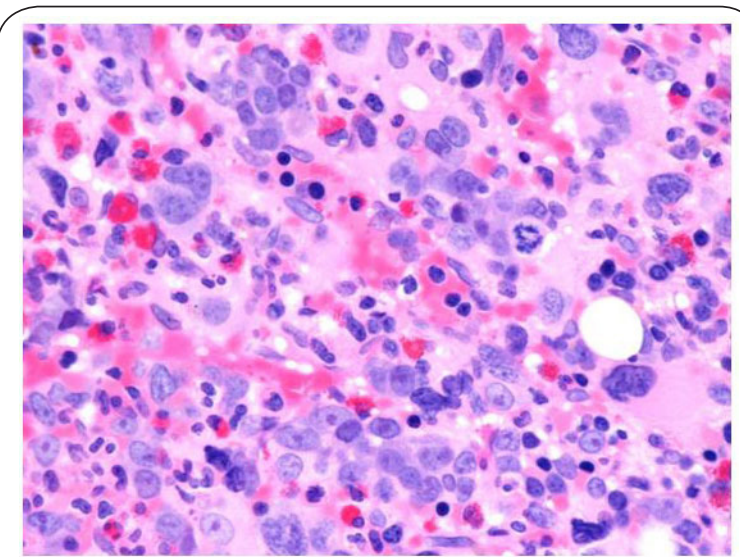

Figure 3. High power of $\mathrm{H} \& \mathrm{E}$ bone marrow trephine biopsy showing hypercellular marrow with infiltration by immature, mononuclear cells with one or more nucleoli.

was submitted for morphologic, cytogenetic, molecular, and flow cytometric immunophenotypic analysis. A diagnosis of acute myeloid leukemia (AML, NOS) according to WHO 2008 classification and AML M5a according FAB classification, with aberrant expression of CD79a, CD56 and CD7 was established. Unfortunately, the patient died from sepsis during standard induction chemotherapy for AML.

\section{Morphologic analysis}

A blast population was identified representing $21 \%$ of the white blood cells in the peripheral blood and $40 \%$ of the bone marrow nucleated hematopoietic cells. In the peripheral blood film and bone marrow aspirate, the blast cells were medium to large size with dispersed chromatin with one or more nucleoli, the cytoplasm is relatively abundant in the majority of blast cells with variable degree of basophilia (Figure 1). In bone marrow core biopsy, the marrow was hypercellular for age (90-100\%) and infiltrated by abnormal immature cells which stain positive for CD34, CD117 and negative for TdT and CD3 (Figures 2,3,4 and 5).

\section{Flow cytometric analysis}

Flow cytometric analysis of the patient's bone marrow demonstrates a discrete blast population gated using side scatter versus $C D 45$. The blast cells showed positivity for CD45, HLA-DR, CD38, CD34, CD33, CD64 (75\%), CD117 (22\%), MPO is expressed only in $15 \%$ of gated cells. CD79a, CD56, and CD7 were expressed in $44 \%, 70 \%$, and $80 \%$ of the blast cells respectively. Terminal deoxynucleotidyl transferase (TdT), CD19, CD20, CD22, CD10, CD13, CD15 and T-cell markers were negative (Figure 6).

\section{Cytogenetic analysis}

We performed interphase cytogenetics, fluorescence in situ 


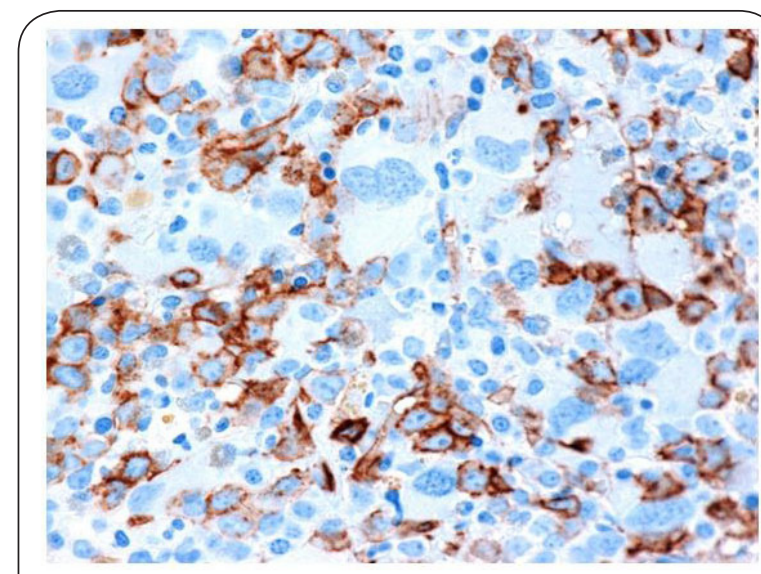

Figure 4. Immunohistochemistry showing the blast cells stained positive for CD34.

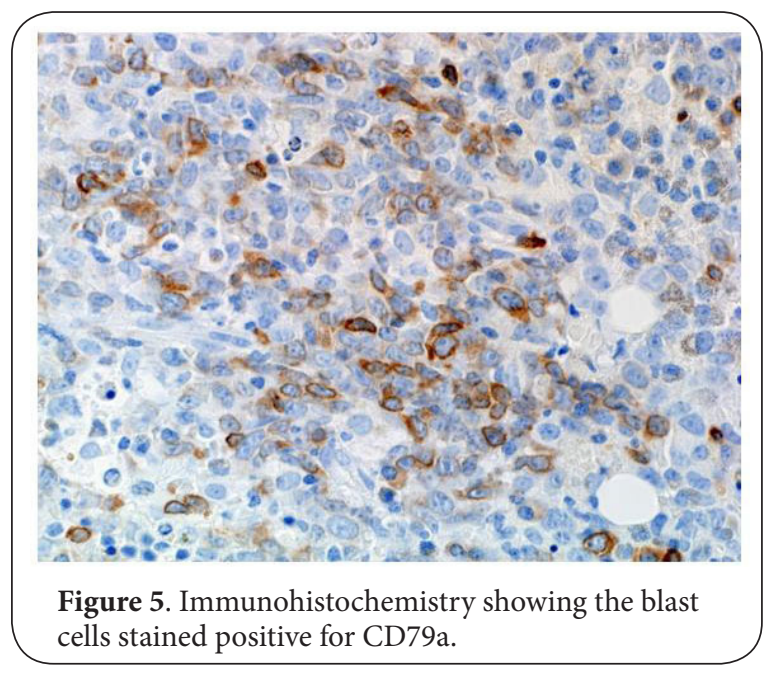

hybridization (FISH) to ascertain the presence or absence of ALL and AML specific abnormalities. Cytogenetic/ FISH studies were negative for specific abnormalities for both AML and ALL panel including ABL- BCR, ETV6RUNX1, TCF3-PBX1, MLL and MYC genes for ALL and PML-RARA, AML1-ETO, CBFB, CEP8/D8Z2 and MLL genes for $A M L$, the result was reported according to ISCN 2009 as follow nuc ish (ABL1,BCR)x2[100]/(ETV6,RUNX1) $\times 2[100] /\left(5^{\prime} \mathrm{MLL}, 3^{\prime} \mathrm{MLL}, 5^{\prime} \mathrm{MLL}\right.$ con 3'MLL $\times 2[100] /\left(5^{\prime} \mathrm{MYC}\right.$ 3'MYC, 5'MYC con 3'MYC)x2[100]/(TCF3,PBX1)x2[100]/

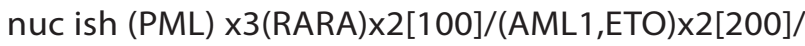
(5'CBFB,3'CBFB,5'CBFB con 3' CBFB) x2[100]/(D8Z2)x2[100]. Trisomy 15 was detected in $47 \%$ of the studied cells as solo abnormality.

A PCR-based assay was performed showed no clonal immunoglobulin gene rearrangement.

\section{Discussion}

Flow cytometric immunophenotyping has become

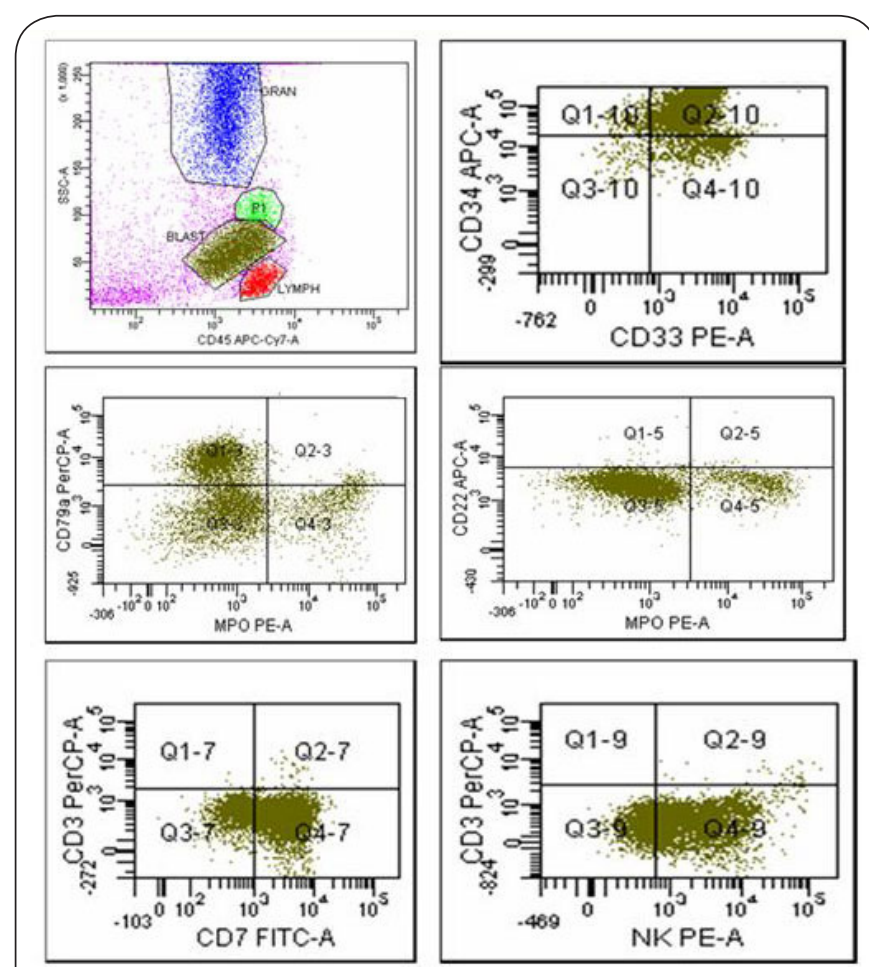

Figure 6. Flow cytometric immunophenotypic analysis of the blasts reveals constitute $40 \%$ of BM cells and expressed CD33, CD34.The lymphoid-associated markers CD79a, CD56(NK) and CD7 are expressed in $44 \%, 70 \%$ and $80 \%$ of blasts respectively. MPO is partially expressed (15\%) and negative cCD22and CD3.

an important diagnostic tool for the classification of acute leukemias. The aberrant expression of selected markers in acute myeloid leukemic cells has been associated with relapse and biological aggressiveness [12]. There have been many reports of unusual immunophenotypic expression in AML with the prediction of impending relapses prior to clinical manifestations [13-16].

CD79a is a highly lineage-specific marker of B lymphoid cells and plays an important role in the diagnosis of acute leukemia [17]. Its expression in AML, however, is less extensively described than for CD7 and CD56. The prognostic meaning of CD79a expressions in AML is still a controversial matter; Frater et al., [7] reported four of the 46 patients were CD79a positive, the prognostic significance in these cases is unclear. Another study done by Chung et al., [17] ,found Five patients among 68 AML with $\mathrm{t}(8 ; 21)$ (q22;q22) revealed CD79a positive reaction, the survival probability of the CD79a expression group was significantly lower than classical AML with $t(8 ; 21)$ (q22; q22). However, these results in both studies should be treated with reservation due to relatively small sample sizes and further studies are needed for assessment the prognostic relevance of CD79a expression in AML.

A similar study done by Kozlov et al., [18] showed 2 cases 
Elyamany et al. Pathology Discovery 2013,

http://www.hoajonline.com/journals/pdf/2052-7896-1-6.pdf

doi: 10.7243/2052-7896-1-6

among 89 cases of AML showed strong coexpression of CD79a, both cases were demonstrated the $t(8 ; 21)$ with cytogenetics and the AML1/ETO rearrangement with FISH, although the immunophenotyping met proposed scoring criteria for a diagnosis of Biphenotpic acute leukaemia (BAL), the cytogenetic and FISH findings indicate that CD79a represented the aberrant presence of a B-cell antigen in leukemias of distinct myeloid linage. Accordingly, we think that, the high score given to CD79a by EGIL is questionable based on cytogenetic classification.

Apparently, these markers were expressed early in hematopoietic ontogeny in the lesser-differentiated acute myeloid leukemia subtypes, including FAB M0, M1, and M2 [3]. Saxena et al., [6] found that CD7 expression in AML is associated with the immature antigens CD34, HLA-DR, and $\mathrm{TdT}$, these findings are in accordance with our results except for TdT which was negative, they also contend that AML with CD7 may originate from early hematopoietic precursors and indicate biologic aggressiveness in a significant proportion of patients. Tiftik et al., [19] found CD7 positivity in 7 of $12 \mathrm{AML}$ patients and CD56 expression in 3 AML patients and revealed that CD7 and CD56 expression at diagnosis was associated with a low remission rate and biological aggressiveness in $A M L$ patients. Suzuki et al., [20] revealed poor prognosis in AML in which CD7 and CD56 were aberrantly expressed. Regardless of $\mathrm{CD} 7$ positivity, sole expression of CD56 in AML has been shown to be a predictor of lower complete remission rates and shorter survival $[\mathbf{2 1 , 2 2 ]}$.

\section{Conclusion}

This study demonstrates that CD79 expression in acute leukemia is not restricted to B-ALL and may be aberrantly expressed in AML and T-ALL. The high score given to CD79a by EGIL is questionable based on cytogenetic classification. The prognostic significance of selected markers of leukemic cells is well known, CD7 and CD56 expression at diagnosis has been associated with low remission rates and biological aggressiveness in a significant proportion of acute leukemias, however, the prognostic relevance of expression of CD79a in $A M L$ is unclear and need further studies. The aberrant expression of CD7, CD56, and CD79a, representing the capacity of these leukemias for trilineal expression of leukocyte differentiation antigens.

\section{List of abbreviations}

AML: Acute Myeloid Leukemia

EGIL: The European Group for the Immunological

Characterization of Acute Leukemia

CD: Cluster of Differentiation

ALL: Acute Lymphoblastic Leukemia

MPO: Myeloperoxidase

TdT : Terminal Deoxynucleotidyl Transferase

FISH: Fluorescence in Situ Hybridization

FAB: French-American-British

\section{Competing interests}

The authors declare that they have no competing interests.

Authors' contributions
\begin{tabular}{|l|c|c|c|}
\hline Authors' contributions & GE & KF & AA \\
\hline Research concept and design & $\sqrt{ }$ & $\sqrt{ }$ & $\sqrt{ }$ \\
\hline Collection and/or assembly of data & $\sqrt{ }$ & $\sqrt{ }$ & $\sqrt{ }$ \\
\hline Data analysis and interpretation & $\sqrt{ }$ & -- & -- \\
\hline Writing the article & $\sqrt{ }$ & -- & -- \\
\hline Critical revision of the article & $\sqrt{ }$ & -- & $\sqrt{ }$ \\
\hline Final approval of article & $\sqrt{ }$ & $\sqrt{ }$ & $\sqrt{ }$ \\
\hline Statistical analysis & $\sqrt{ }$ & -- & -- \\
\hline
\end{tabular}

\section{Acknowledgement}

I thank Dr. Omar Alsuhaibani, Head Division of Hematology and Blood Bank for every support in the lab. I also thank

Abdelrahman Elarja, Flowcytometry specialist for his assistance in Flowcytometry.

\section{Publication history}

Editor: Markus H. Frank, Harvard Medical School, USA.

Received: 15-Jul-2013 Revised: 31-Aug-2013

Accepted: 15-Sep-2013 Published: 23-Sep-2013

\section{References}

1. El-Sissy AH, El-Mashari MA, Bassuni WY and El-Swaayed AF. Aberrant lymphoid antigen expression in acute myeloid leukemia in Saudi Arabia. J Egypt Nat/ Canc Inst. 2006; 18:244-9. I PubMed

2. Bene MC, Castoldi G, Knapp W, Ludwig WD, Matutes E, Orfao A and van't Veer MB. Proposals for the immunological classification of acute leukemias. European Group for the Immunological Characterization of Leukemias (EGIL). Leukemia. 1995; 9:1783-6. | Article | PubMed

3. Cruse JM, Lewis RE, Pierce $S$, Lam J and Tadros $Y$. Aberrant expression of CD7, CD56, and CD79a antigens in acute myeloid leukemias. Exp Mol Pathol. 2005; 79:39-41. | Article | PubMed

4. Khalidi HS, Chang KL, Medeiros LJ, Brynes RK, Slovak ML, MurataCollins JL and Arber DA. Acute lymphoblastic leukemia. Survey of immunophenotype, French-American-British classification, frequency of myeloid antigen expression, and karyotypic abnormalities in $\mathbf{2 1 0}$ pediatric and adult cases. Am J Clin Pathol. 1999; 111:467-76. | Article I PubMed

5. Khalidi HS, Medeiros LJ, Chang KL, Brynes RK, Slovak ML and Arber DA. The immunophenotype of adult acute myeloid leukemia: high frequency of lymphoid antigen expression and comparison of immunophenotype, French-American-British classification, and karyotypic abnormalities. Am J Clin Pathol. 1998; 109:211-20. | Article I PubMed

6. Saxena A, Sheridan DP, Card RT, McPeek AM, Mewdell CC and Skinnider LF. Biologic and clinical significance of CD7 expression in acute myeloid leukemia. Am J Hematol. 1998; 58:278-84. | Article | PubMed

7. Frater JL, Yaseen NR, Peterson LC, Tallman MS and Goolsby CL. Biphenotypic acute leukemia with coexpression of CD79a and markers of myeloid lineage. Arch Pathol Lab Med. 2003; 127:356-9. | Article | PubMed

8. Arber DA, Jenkins KA and Slovak ML. CD79 alpha expression in acute myeloid leukemia. High frequency of expression in acute promyelocytic leukemia. Am J Pathol. 1996; 149:1105-10. | PubMed Abstract | PubMed Full Text

9. Blakolmer K, Vesely M, Kummer JA, Jurecka W, Mannhalter C and Chott A. Immunoreactivity of B-cell markers (CD79a, L26) in rare cases of extranodal cytotoxic peripheral T- (NK/T-) cell lymphomas. Mod Pathol. 2000; 13:766-72. | Article | PubMed

10. Pilozzi E, Pulford K, Jones M, Muller-Hermelink HK, Falini B, Ralfkiaer E, Pileri S, Pezzella F, De Wolf-Peeters C, Arber D, Stein H, Mason D and Gatter K. Co-expression of CD79a (JCB117) and CD3 by lymphoblastic 
Elyamany et al. Pathology Discovery 2013,

http://www.hoajonline.com/journals/pdf/2052-7896-1-6.pdf

Iymphoma. J Pathol. 1998; 186:140-3. | Article | PubMed

11. Campana D and Behm FG. Immunophenotyping of leukemia. J Immunol Methods. 2000; 243:59-75. | Article | PubMed

12. Head DR. Revised classification of acute myeloid leukemia. Leukemia. 1996; 10:1826-31. | Article | PubMed

13. Campana $D$, Coustan-Smith $E$ and Janossy $G$. The immunologic detection of minimal residual disease in acute leukemia. Blood. 1990; 76:163-71. | Article | PubMed

14. Coustan-Smith E, Behm FG, Hurwitz CA, Rivera GK and Campana D. $\mathrm{N}$-CAM (CD56) expression by CD34+ malignant myeloblasts has implications for minimal residual disease detection in acute myeloid leukemia. Leukemia. 1993; 7:853-8. | Article | PubMed

15. Drach J, Gattringer C and Huber H. Combined flow cytometric assessment of cell surface antigens and nuclear TdT for the detection of minimal residual disease in acute leukaemia. Br J Haematol. 1991; 77:37-42. | Article | PubMed

16. Reading $\mathrm{CL}$, Estey $\mathrm{EH}$, Huh YO, Claxton DF, Sanchez G, Terstappen LW, O'Brien MC, Baron S and Deisseroth AB. Expression of unusual immunophenotype combinations in acute myelogenous leukemia. Blood. 1993; 81:3083-90. | Article | PubMed

17. Chung HJ, Chi HS, Cho YU, Lee EH, Jang S, Park CJ and Seo EJ. [Prognostic effect of cytoplasmic CD79a expression in acute myeloid leukemia with t(8;21)]. Korean J Lab Med. 2007; 27:388-93. | Article | PubMed

18. Kozlov I, Beason K, Yu C and Hughson M. CD79a expression in acute myeloid leukemia $t(8 ; 21)$ and the importance of cytogenetics in the diagnosis of leukemias with immunophenotypic ambiguity. Cancer Genet Cytogenet. 2005; 163:62-7. | Article | PubMed

19. Tiftik N, Bolaman Z, Batun S, Ayyildiz O, Isikdogan A, Kadikoylu G and Muftuoglu $E$. The importance of CD7 and CD56 antigens in acute leukaemias. Int J Clin Pract. 2004; 58:149-52. | Article | PubMed

20. Suzuki R, Ohtake S, Takeuchi J, Nagai M, Kodera Y, Hamaguchi M, Miyawaki S, Karasuno T, Shimodaira S, Ohno R, Nakamura $S$ and Naoe T. The clinical characteristics of CD7+ CD56+ acute myeloid leukemias other than M0. Int J Hematol. 2010; 91:303-9. | Article | PubMed

21. Raspadori D, Damiani D, Michieli M, Stocchi R, Gentili S, Gozzetti A, Masolini P, Michelutti A, Geromin A, Fanin R and Lauria F. CD56 and PGP expression in acute myeloid leukemia: impact on clinical outcome. Haematologica. 2002; 87:1135-40. | Article | PubMed

22. Alegretti AP, Bittar CM, Bittencourt R, Piccoli AK, Schneider L, Silla LM, Bo SD and Xavier RM. The expression of CD56 antigen is associated with poor prognosis in patients with acute myeloid leukemia. Rev Bras Hematol Hemoter. 2011; 33:202-6. | Article | PubMed Abstract | PubMed Full Text

\section{Citation:}

Elyamany G, Fadalla k and Abdulaaly AA. Abnormal expression of CD79a, CD56 and CD7 in acute myeloid leukemia. Pathol Discov. 2013; 1:6. http://dx.doi.org/10.7243/2052-7896-1-6 